\title{
Royal Society of Medicine
}

a strand is seen running from the posterior margin of the membrane towards the short process of the malleus, probably the chorda tympani.

Mr SyDNEY Scort (President) said he had not seen a similar case. The only means that occurred to him of settling the matter was by Sectio.

Dr H. SMURTHWAITE said that this patient had evidently had suppurative otitis media. There was a large calcareous deposit in the lower portion of the drum extending from side to side. He doubted whether what one saw as a grey streak just below Shrapnell's membrane was the chorda tympani.

Sir William Milligan said he did not think there was a calcareous deposit in this case, but there was evidence of old catarrh on both sides. Mr Cheatle had shown a similar case before the Section some years ago.

Case of Extreme Unilateral Deafness to Sounds by Air, but with Good Bone Conduction in the Affected Ear-A. R. FrieL, M.D.-Male, aged $3^{8}$, was in the artillery for some years and had no noticeable deafness. Six years ago he was buried by a shell explosion and was unconscious for three days. About five days later, when in hospital, he noticed he was deaf in the left ear.

Condition in 1922 : Hearing, right ear, conversational voice $19 \mathrm{ft}$., whisper $\mathrm{I}_{5} \mathrm{ft}$. Left ear, nil by air. The tuning-fork on the right mastoid referred to the left ear. Watch heard on left mastoid. Cochlear-palpebral reflex absent on left side, present on right. Syringing left ear with cold water causes nystagmus : and clockwise rotation produces nystagmus lasting twenty-five seconds. The right and left drums are intact.

Dr FRIEL explained that he brought this case to show that when a pensioner complained of deafness he should not be disbelieved because he had good bone conduction.

\section{ABSTRACTS}

\author{
THE EAR
}

Frequency of Bilateral Lesions of Shrapnell's Membrane. LUBETBarbon and Labernadie. (Annales des Maladies de l'Oreille, December I 923 .)

Marchetti and Rivini described an orifice in the membrana flaccida. Other anatomists disagreed as to the constant presence of this orifice. Bezold did not find it in the newly-born. Zaufal and Schmiegelow stated that the foramen was pathological, and most workers agreed with this decision. All agree, however, that there is a part of the 


\begin{abstract}
s
membrane which, from structural reasons, is much less resistant than the remainder.

Where there is a suppurative perforation of Shrapnell's membrane, the perforation is often bilateral and symmetrical. Where one side seems to be healthy, often there is to be found on the other side, in the corresponding site, a dehiscence such as that described by Rivini. It may be, therefore, that, either on account of the persistence of the perforation, or because this is the weakest part of the membrane, certain patients are liable to have the perforation in this part of the membrane. Sometimes the patient complains only of one ear, but inspection of the other reveals a perforation closed by a dry crust, the removal of which shows pus behind. Gavin YOUNG.
\end{abstract}

Suppurative Otitis Media treated by Zinc Ionization. T. B. Jobson, M.D. (Brit. Med. Journ., Ist March 1924.)

This is a record of 45 discharging ears treated by ionization, with 29 cures. Of these, 22 required only one treatment, 4 were ionized twice, 2 of them three times, and only $\mathrm{I}$ four times.

The author says that if a case does not dry up after two or three applications of the treatment it is not likely to yield at all. Attic perforations and cholesteatoma cases respond badly, and the treatment is not suitable for acute and subacute otorrhoea. It is claimed that the high percentage of cures is a complete refutation of the opinion held by some that a chronic ear discharge always means suppuration in the tympanic antrum.

The advantages claimed for the treatment are:-

I. It will cure any case of otorrhoea which is curable by drops.

2. It will accomplish this in one-hundredth part of the time.

3. It will cure a large number of cases which do not respond to other forms of treatment.

T. Ritchie Rodger.

Mastoidectomy zeithout opening the Antrum in exceptional Cases with Prominence of the Lateral Sinus. Dr A. Nepveu, Paris. (Bulletin d'Oto-Rhino-Laryngologie, November 1923.$)$

The author recalls a case reported by himself at the tenth Congrès International d'Oto-Rhino-Laryngologie, $\mathrm{x}_{922}$ (q.v.). A girl of $\mathrm{I} 5$ had a Bezold's abscess. At the operation it was found that the lateral sinus came forward to within $4 \mathrm{~mm}$. of the auditory meatus, and the antrum could not be reached. The tip of the mastoid process was entirely removed, the wound drained, and complete recovery followed.

In the present case, a woman of $\mathbf{3}^{2}$ had an acute otitis media, for which myringotomy was performed. Healing followed, but three months later she returned deaf. The membrana tympani was dull, not red or bulging; pain behind the mastoid process. Ten days 280 


\section{The Ear}

later a mastoid abscess was apparent; myringotomy let out a small drop of pus. At operation pus was found at a depth of half a centimetre within the mastoid process. The whole of the tip of the process was removed; but it was found that the lateral sinus came so far forward, that it was a physical impossibility to reach the antrum, unless a radical operation were performed. The wound was therefore drained without opening the antrum, with the happiest results.

Dr Nepveu, while believing that proper opening of the antrum is ordinarily of prime importance, is forced to conclude that there are cases, especially of posterior mastoid infection, where a severe mastoiditis can coexist with a healthy antrum. (Cf. Kümmel, Acta Otolaryngologica, abstracted in Journal of Laryngology, 1923, p. 606E. W.-W.) When the prominence of the sinus denies all access to the antrum, it may be better to leave matters as they are, rather than to go on to perform a radical mastoid operation: opening the antrum is not invariably essential for cure.

E. WatSON-Williams.

Blood Transfusion for Otological Diseases. Dr Unger. (Laryngoscope, Vol. xxxiii., No. 4, p. 250.)

The use of whole unmodified blood is recommended in cases of bacteræmia, and the method adopted is very simple. The mechanical principle involved in the instrument used is the establishment of two channels by means of which a record syringe is automatically connected alternately with a vein of the donor and then with one of the recipient. In this way, the channel which is not being used for injection or aspiration of blood is being flushed with saline. No clotting takes place, as the barrel of the syringe is sprayed with ether. The use of unmodified blood is preferable to citrated blood when the transfusion is intended to combat infections or diseases of the blood.

Andrew Campbell.

Intracranial Complications of Otitic Origin. Dr Otto Fleischmann. (Folia Oto-Laryngologica, Vol. xxi., Nos. 6 to 8, p. 2 I 7.)

Having made a study of the literature during the last year, the author reviews the progress in diagnosis and treatment of intracranial complications arising from the ear. Mention is made of thrombosis of the condyloid veins; the anterior vein may infect the occipito-atlantoid joint, whereas the posterior may give rise to abscesses between the cervical vertebræ and the deep muscles of the neck through their anatomical connections. The chief symptom in each case is fixation and contracture of the neck.

In genuine meningitis Dandy's reaction is always positive. Dandy and other workers have made an advance in the diagnosis of tumours of the brain by the introduction of encephalography, which consists

vol. XXXIX. No. v. 


\begin{abstract}
s
in filling the ventricles or the spinal canal with air and taking radiographs. The latter procedure is the less dangerous, and 80 to I 00 c.c. of cerebro-spinal fluid may be replaced by air. The method is successful in localising tumours, and is also useful in otitic intracranial complications. In the operative treatment of brain abscess, Boenninghaus recommends the removal of brain matter equal in diameter to the trephine opening, so as to prevent dead spaces. There is an ample bibliography.

Andrew Campiell.
\end{abstract}

\title{
THE NOSE
}

The Utility of the Nose. Owen F. Paget, M.D. (Practitioner, March 1924.)

The nose is considered as possessing three divisions: (I) the cartilaginous nose; (2) the bony nose or antibody producer with its sense of smell; (3) the nasopharynx or negative pressure chamber. Sketches are shown of various types of nose to demonstrate how the "nozzle-effect" of their shape influences the passage of air into the cavity. The ethmoidal structures act as baffles, and the epithelial cells, furnished with cilia, are able to pass an excess of particles in definite directions. The destruction and ingestion or absorption of bacteria by the epithelial cells lead to the production of antibodies which, diffusing into the circulation, are used in other situations attacked by similar organisms. The author considers the following important causes of obstruction do not receive due consideration-(I) too weak cartilages; (2) folds of mucous membrane on the inside of the cartilaginous nose, lying on the septum; (3) too close proximity of the front of the middle turbinal to the nasal bone and septum.

Interference with the proper nozzle-effect from any such cause or from atrophy of the turbinals means that the air simply drifts into the nose instead of being efficiently sucked in, with resulting diminished antibody production and diminished sense of smell.

T. Ritchie Rodger.

Large Cystic Polypus of the Nose in a Child aged seven. Professor Gugliemo Bilanchion.. (Archiv. Italian di Laringologia, Anno xlii., fasc. 3, January 1923.)

The author points out the comparative rarity of nasal polypi in young children. He gives a list of reported cases-the earliest being in a child of two days - and two congenital cases are mentioned. $\mathrm{He}$ follows Kaufmann's analysis of polypi into two main groups : $(a)$ in 282 


\section{The Nose}

which the elements of the mucosa are represented hypertrophied but not altered, and $(b)$ in which degenerative processes have taken place.

Cystic polypus is included in the first group, and Professor Bilanchioni records a case in a girl of 7 with a history of five years. The author removed the polypus under local anæsthesia. It consisted of a lower solid pole and an upper cystic part. Sections showed the solid portion to be partly myxomatous and partly fibrous with a rich vascular supply.

The author states that cysts of the nose and accessory sinuses are due to the retention of secretion in the various mucous glands of the lining membrane. The cystic portion of the polypus had a fibrous lining but no epithelium.

F. C. Ormerod.

\section{Calcification of the Inferior Turbinals in a case of Nasal Tuber- culosis. Grorgio Ferreri. (Archivii Italiani di Laringologia, December I923.)}

A girl of 13, with a good previous history, had suffered from tuberculous hip-disease from which she recovered. A short time afterwards she developed a persistent cough, and later still a painful dysphagia. On examination she presented enlarged mediastinal glands, disease of both apices, and ulceration of the Jarynx and pharynx. The nasal passages were blocked by two whitish masses which were hard to the touch of a probe. These masses obstructed the view of the hinder part of the nasal cavities and caused obstruction to nasal breathing. The septum appeared healthy. The patient was very weak and anæmic, and had a very poor circulation.

After a short time in hospital she spontaneously expelled the two whitish masses, which on examination proved to be the two inferior turbinal processes which had become completely calcified-both mucosa and bony structure. Microscopical examination showed that as the result of the tuberculous disease and the poor circulation, a hyaline degeneration followed by calcification of the whole process had occurred, with eventual separation.

F. C. ORMEROD.

The Radiography of the Sella Turcica. Robert Knox, M.D. (Archives of Radiologv and Electro-Therapy, November and December 1923.)

The author gives a brief history of the radiographic studies of the sella turcica and surrounding structures, with abstracts from the various articles on the subject. A description of the technique is:given, and an attempt has been made to outline simple methods of measurement to show the relations between the surface of the head and the bony and soft parts of the interior. A base line is used, which may 


\section{Abstracts}

be called the radiographic base line of the skull, determined by drawing a line from the nasion through the centre of the external auditory meatus, and continuing it to the mid-line at the back of the head.

On this horizontal plane are found: the lower part of the frontal sinus, the sphenoidal sinus, the apex of the petrous bone, the glenoid cavity and condyle of the lower jaw, the external auditory meatus, the jugular foramen, and the mastoid process.

Three perpendicular lines divide the head into four regions: one region of which contains between one-third distance and one-half distance the body of the sphenoid, the greater portion of the sphenoidal sinus, the sella turcica, and the anterior part of the temporosphenoidal lobe.

"As an illustration of the use of this method, the radiography of the sphenoidal sinus laterally may be cited. The method shows that the base line runs through the sinus, which is situated between the intersecting lines at the one-third and one-half distance. The tube is therefore arranged so that its central rays pass through the base line and between the intersecting lines." The patient may be radiographed with the head in either the vertical or horizontal position; or one of the many head-rests may be used to steady the head in any position.

A brief description of the apparatus for the radiography of the skull is appended. The author then gives a description of the sella turcica in its anatomical relations and measurements. Very fine photographs are included, showing the effect of correct and incorrect centering of the tube.

G. Ewart Martin.

\section{THE LARYNX} "Singers' Nodules" and Phonasthenia. IMHOFER, Prag. (Zeitschrift
fiir Hals-, Nasen-, und Ohrenheilkunde, Bd. 6, Part II., p. 540.)

The question is whether the phonasthenia is due to the nodules or the nodules formation due to the phonasthenia. The nodules are the result of forcible pressure of the cords on each other in the place of simple apposition, and this forcible inter-pressure is the result of straining efforts to overcome the vocal weakness. In some cases, however, the anatomical structure of the cord is more favourable to the formation of nodules than in others. A symptom common to both is faulty intonation (Detonierung), and if the nodules are large there is a loss of tone from escape of air. Imhofer finds vocal gymnastics unavailing in the treatment of nodules, and nothing of any use except absolute silence. He makes no reference to Holbrook Curtis's exercises.

James Dundas-Grant.

$$
284
$$




\section{The Larynx}

\section{A Typical Form of Laryngeal Cancer. Dr M. Hajek. (Zeitschrift}

fïr Laryngologie, Rhinologie, etc., December 1923.)

This article is a study of the evolution of malignant new growth of the larynx as illustrated by four very carefully observed cases in adults. Typical multiple papillomata preceded the condition in two of them. These were observed for three years, during which time the tumours were removed by the indirect method on many occasions. Ultimately the neoplasms became definitely malignant. In the first-mentioned instance the papilloma was of the diffuse spreading type involving the trachea. The author thinks that it is unprofitable to discuss the question whether this form of papilloma was malignant from the commencement or whether a metaplasia took place. When no infiltration into the underlying tissue can be shown under the microscope, the innocent character of the tumour must be accepted. Only serial sections of the whole larynx and trachea at the time when the condition was first noticed could have proved that carcinoma existed from the beginning. This is obviously out of the question.

In the other cases the carcinoma was preceded by a small polypoid tumour which appeared growing in the situation usual for "singers' nodes." Hajek was able to observe the last case mentioned in his article for a perjod of two years, and noticed how a small-stalked tumour gradually became sessile and flattened out on the left cord. A further three months' delay showed diffuse infiltration of the whole cord, and the diagnosis could no longer be in doubt. J. KEEN.

\section{A Neze Form of Incision in Gluck's Laryngectomy. OTto Mayer, Vienna. (Zeitschrift fiir Hals-, Nasen-, und Ohrenheilkunde,} Vol. vi., Part II., p. 544.)

In order that the incisions may not lie one above the other, and that a hollow space should not be left when the larynx has been removed, Mayer practises a new form of incision. First, a square flap is cut with its base at the hyoid bone and its free lower margin at the level of the cricoid cartilage. This is turned up with the subjacent platysma. The extirpation is carried out according to Gluck's method, but the larynx is separated from the pharynx from below upwards. The pharynx is then closed in the usual way. The flap is then turned down and united to the skin margin in such a way that no hollow remains between the skin and the pharyngeal mucous membrane. As the flap is too short to close round the severed trachea, a median and two lateral incisions are made running downwards so that two tongue-shaped flaps are formed. The trachea is carefully stitched in the mesial incision, and the sides of the flaps are so stitched up that they can be attached to the lower margin of the upper square flap without dragging on it. 


\begin{abstract}
s
Remarks on the Operation of Total Laryngectomy. Professor voN Hofmeister. (Zeitschrift fiir Laryngologie, Rhinologie, etc., December r923.)
\end{abstract}

The present number of this Journal is dedicated to Professor Gluck, a pioneer in these extensive operations. Von Hofmeister mentions some extremely interesting points in connection with technique, after describing unusual complications which occurred in several of his cases. One of these may be mentioned more fully, as the sequence of events seems particularly instructive. The operation was done under local anæsthesia, i.e., prevertebral injections on both sides and infiltrations of both superior laryngeal nerves. The transverse collar incision of the Kocher type was used but at a somewhat higher level than is usual for goitre operations. In this particular instance severe dyspnoa occurred shortly after opening the pharynx and at the time when the larynx was pulled forward out of the wound. This difficulty was suddenly complicated by a big venous hamorrhage from the right jugular. In the hurry of the moment it was very natural for the surgeon rapidly to snatch up an artery clamp and to fix it blindly upon the bleeding area but without any success. Temporary pressure by a gauze pad had to be used, while the dyspnoea, by now extremely urgent, was relieved by pushing a rubber catheter through the diseased larynx. Returning to the hæmorrhage, von Hofmeister found that a hole had been torn into the right internal jugular vein and this was repaired by a continuous catgut suture. No further difficulties occurred.

The next morning the patient showed paralysis of the left arm, later complete hemiplegia, then coma, and death occurred two days after operation. The post-mortem examination showed an anæmia of the right cerebral hemisphere with areas of softening. A clot was found filling up all the ramifications of the middle cerebral artery down to small branches of $\mathrm{I} \mathrm{mm}$. diameter. When traced downwards, this revealed a complete thrombosis of the right common carotid, the occlusion of the artery beginning at the level where the jugular vein was repaired during operation. The latter was quite intact along the line of suture. The interior of the common carotid showed a tear in the intima, on the lower edge of which could be seen distinctly the impression of the teeth of an artery clamp. The injury was done at the time of the jugular hæmorrhage when the hurried attempt at hæmostasis was made. The artery forceps included in its grasp a portion of the artery lying behind the vein and produced a small tear of the inner lining. The trauma of the artery wall was the immediate cause of the fatal issue. The author is inclined to blame primarily the dyspnoa which occurred when the larynx was detached from the pharynx. The resulting venous congestion caused a bursting 


\section{The Larynx}

of the jugular vein at a point where a ligature had been placed in the earlier stages of the operation. The difficulty would have been avoided if a tracheotomy had been done as a first step, and this method is now invariably adopted by the author. A separate button-hole incision is made in the mid-line below the collar incision, the trachea is divided and the upper end carefully stitched into the wound. The lower end of the larynx is shut off by a tightly-fitting iodoform gauze plug which can be fixed by a suture and which then provides a useful hold in further manipulations of the larynx.

The separation of the voice-box is then undertaken from below upwards. Here the author differs from Gluck, who recommends the method from above downward. The advantage of the former seems to be ( $I$ ) the absence of hurry and the fact that there is no possibility of sudden dyspnœa; (2) more certain asepsis by shutting off the septic and carcinomatous area. It will be remembered that in the case described, a rubber cannula was pushed through the larynx, and the danger of dissemination of cancer cells is not to be underestimated.

Preliminary tracheotomy, i.e, a separate operation performed three or four days, or even so long as ten days beforehand, is a sine quâ non in America, and probably in England also, if we can judge from such a well-known text-book as Loeb's Operative Surgery. But this apparently finds no favour in the German clinics. The main function of the preliminary operation is to protect the mediastinum by a barrier of granulation against septic infection. It is difficult to decide why this danger looms so largely in Anglo-American laryngological literature, while seemingly ignored in the German accounts. The most striking difference in the planning of these operations is in the type of anæsthetic used-general, as against local, with very few exceptions. Can this be responsible for the marked difference in outlook when considering operations on the air passages? J. KEEN.

On the Mechanism of Speech after Complete Laryngectomy. Dr Hugo STERN. (Zeitschrift fiir Laryngologie, Rhinologie, etc., December I923.)

Any form of speech, after this serious operation, has in our minds always been associated with the use of an artificial apparatus fitting over the permanent tracheotomy opening. Those who attended the Paris Congress, in 1922, will recall the series of cases shown by Tapia of Madrid. On the contrary, Dr Stern's patients have nearly all succeeded, after considerable practice, in evolving a form of physiological speech, the mechanism of which is discussed.

Before any sound can be produced, a suitable quantity of air has to be swallowed. By appropriate movements of the abdominal wall and 


\begin{abstract}
s
œsophageal musculature this is forcibly expelled, and the blast of air thus produced can to some extent replace the action of lungs and glottis.

Which Organ replaces the Lung in storing the Air required? The methods of investigation are the following :-

(I) Auscultation of the chest wall front and back, also of the neck region during the production of speech.

(2) $X$-ray screening of thorax and abdomen. The author finds that in approximately 50 per cent. of the cases, the stomach acts as the reservoir of air-especially the fundus part of it. The left dome of the diaphragm is generally at a higher level than the right (normally it should be the reverse). This is due to a definite enlargement of the stomach fundus in all directions, which occurs as a result of these peculiar speech exercises. In other cases the œsophagus or hypopharynx dilates to hold the necessary air.
\end{abstract}

Which Organ replaces the Glottis? This is a much more difficult question to answer. Observations with the laryngoscopic mirror are nearly always out of the question. The pulling forward of the tongue or raising the soft palate usually makes it impossible for the patient to perform the complex muscular act in which all the structures of the pharynx and mouth take an active part. From post-mortem observations in cases which died of recurrence after acquiring this voice, and from mirror examination in a few patients where this was possible, the author concludes that the pseudo-glottis is formed most frequently in the following situations:-

(a) Between back of tongue and posterior pharyngeal wall.

(b) Between tongue and soft palate.

(c) Between the posterior pillars of the fauces.

(d) Between the epiglottis and two muscular ridges which form the hypopharynx.

(e) At the upper end of the œesophagus.

According to Dr Stern, during the performance of complete laryngectomy the surgeon can, to some extent, lay the foundation for a pseudoglottis. He should preserve any suitable fold of mucous membrane or muscular band. No actual attempts have yet been made in this direction. The co-ordination between the newly-acquired act of speech and normal respiration is discussed, as is also the control of the cardiac opening of the stomach in relation to this new function, and many other interesting points which can hardly be enumerated in a short abstract.

The quality of the voice is, generally speaking, good and by no means without modulation, although the range is naturally somewhat 288 


\section{Local Anæsthetics}

limited as one would expect from a glottis which, even in the most successful case, can only be a poor imitation of the normal organ. The patients are mostly able to follow their usual occupations. Sixteen cases are analysed in detail. One man, after two years' practice, obtained a voice extending over two octaves. For actual details of the exercises required, the reader is referred to previous publications both by Dr Stern and by the authors in his list of references. J. KeEN.

\section{LOCAL ANÆSTHETICS}

Butyn as a Local Anasthetic in Nose and Throat Practice. William Hill, M.D., B.Sc. (Brit. Med. Journ., Ioth November I923.)

A short historical sketch is given of the various agents used for producing local anæsthesia. Butyn is stated to be, not a derivative of cocaine, but chemically related to it. It is said to be twice as potent as cocaine, to act more quickly, and to have a more lasting effect, to be less toxic, to permit of boiling without loss of efficacy, and to give rise to no exhilarating or pleasing effects such as would predispose to its abuse. Among its disadvantages are quoted-the absence of any ischæmic effect, its relative expensiveness as compared with cocaine, and the fact that it is not uniformly reliable. The author concludes that in his opinion butyn cannot take the place of cocaine in our routine procedure, but it is a useful alternative in a few conditions, more especially where cocaine is contra-indicated.

T. Ritchie RODGer.

Butyn as a Local Ancesthetic. Sir St Clair Thomson, M.D. (Brit. Med. Journ., gth February 1924.)

Four cases are described in which the author, having been invited by the Ministry of Health to give butyn a trial, used it before the application of the cautery to the larynx. In two cases the drug was unsuccessful in producing anæsthesia, and cocaine had to be resorted to. In the third, butyn was effective but took longer to act, and, as in the other cases, the free secretion of mucus was very inconvenient. In the fourth case, good anæsthesia was obtained and the application of the cautery was just completed, when the patient was seized with tonic convulsion, afterwards passing through the typical phases of an epileptic seizure. A month later the same patient was treated again under cocaine anæsthesia without any adverse symptoms. The author says that he has never had anxiety in a single case where cocaine was used, and that he will never again use butyn in the larynx.

T. Ritchie RoDger. 


\section{Abstracts \\ Cocaine and its Substitutes. E. Watson-Williams, M.C., Ch.M., F.R.C.S.E. (Brit. Med. Journ., ist December 1923.)}

This paper begins with a survey of the reported cases of fatal cocaine poisoning, and certain conclusions are deduced-e.g., that fatal poisoning from clinical doses is rare; "idiosyncrasy" to cocaine in this sense is not established; that the same dose in strong solution is much more dangerous than in weak; that in vascular, including acutely inflamed, tissues and other situations where the drug may rapidly enter the circulation, very great caution is necessary; that absorption from mucous surfaces is often rapid; and that accidents have become much less common since adrenaline has been in use. It is pointed out that all the substitutes have also their toll of fatalities, and, when considering these in relation to the number of deaths from cocaine, the relative frequency of use must be remembered. Cocaine hydrochloride is fairly stable and can be sterilised by short boiling if alkali is excluded, but the effect of the drug is enhanced by the addition of an alkali. Experiments are described by which the comparative toxicity of different local anæsthetics is estimated. These experiments are still in progress. Special caution is enjoined in the use of butyn which has a toxicity as high as, or higher than, that of cocaine and five deaths from the use of butyn are mentioned.

\section{T. Ritchie Rodger.}

The Possible Substitutes for Cocaine. H. H. DALE, M.D. (Brit. Med. Journ., 22 nd March 1924.)

The writer points out that if convincing evidence were forthcoming that a substance existed having all the local effects of cocaine which assist the surgeon, and which had no tendency to produce addiction, it might be taken for granted that such a substitute would be adopted by the medical profession, and that cocaine would rapidly fall into disuse. Of those substitutes which have been employed, a few have had some measure of success, e.g., beta-eucaine, tropacocaine, stovaine, and the closely related alypine, novocaine, and its higher homologue, butyn.

None of the suggested substitutes can claim to constrict the bloodvessels and produce shrinkage of the mucous membrane, an action of cocaine which, if not always desirable, is considered of great value. The synthesis of cocaine itself has only recently been completed, and has resulted in the production of a series of isomeric cocaines. There is still a large field of synthesis unexplored, and at any time the ideal local anæsthetic may appear-potent, penetrating, astringent, and at the same time free from dangerous properties, whether of immediate toxicity or of habit formation. As to the question of possible addic- 


\section{A Dual-Purpose Wool Carrier}

tion to the substitutes, inquiry would seem to reveal the fact that in countries where drug addiction is widely prevalent, there is no evidence of the development of the habit from local anæsthetics other than cocaine. At the same time, in the absence of recorded cases of such, it would be of interest to know whether any of the substitutes had been found to produce mental exaltation and euphoria comparable to that produced by cocaine, and thus providing a basis for its habit-forming property.

A. Logan Turner.

\section{A DUAL-PURPOSE WOOL CARRIER.}

By B. Seymour Jones, F.R.C.S., Hon. Surgeon Ear and Throat Hospital, Birmingham.

THE double purpose bayonet-shaped wool carrier illustrated here has given such satisfaction that I am prompted to publish a description of it.

Cotton wool twisted around the "business" end is prevented from slipping off during use partly by the splayed-out thin tip and partly by the sand-blasted surface. It serves as a wool carrier for both ear and nose. Any difficulty in removing the wool is surmounted by cutting along the edge with a knife.

The instrument is alternatively used as a probe and for pressing skin or cerumen against the meatal wall to view the tympanic membrane. It is also of unique service for pushing ribbon gauze soaked in anæsthetic solution under a turbinate or between a turbinate and the septum. It does not readily penetrate the gauze, and it can be interposed in a narrower chink than an ordinary probe.

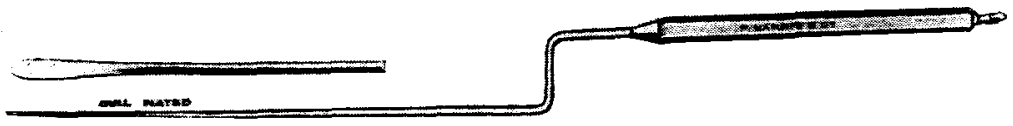

I also use it for conveying B.I.P. to the external auditory meatus in cases of furuncle after incision or rupture, this substance proving, in my experience, the best dressing in preventing recurrence or extension of the affection.

A further use is found in rapidly re-rolling a used bandage, if the hexagonal handle is employed to wind it on and the probe end as a rotatory handle.

The wool carrier is provided in two lengths, one of which is to penetrate to the posterior and upper regions of the nose.

The instrument may be procured from Messrs Philip Harris \& Co, Ltd., Edmund Street, Birmingham. 